\title{
Shift of Serum Osteocalcin Components between Cord Blood and Blood at Day 5 of Life
}

\author{
NOBUHIKO SHIMIZU, MASAAKI SHIMA, HARUHIKO HIRAI, SHIGEO NAKAJIMA, \\ KUMI NISHIMURA, KANJI YAMAOKA, $†$ AND SHINTARO OKADA
}

Department of Developmental Medicine (Pediatrics), Osaka University Graduate School of Medicine, Osaka, Japan [N.S., M.S., H.H., S.N. K.N. S.O.]; Department of Pediatrics, Osaka Prefectural General Hospital, Osaka, Japan [K.Y.]

\begin{abstract}
ABST
Vitamin K deficiency is a relatively common condition in
neonates. However, the role of vitamin $\mathrm{K}$ in neonatal bone
metabolism remains to be determined. Osteocalcin (OC) is the
most abundant noncollagenous protein in bone, and is regulated
to be $\gamma$-carboxylated by vitamin $\mathrm{K}$. In this study, we measured
$\gamma$-carboxylated osteocalcin (Gla-OC) and non- or undercarboxy-
lated osteocalcin (Glu-OC) separately, and examined the effects
of vitamin K on osteocalcin metabolism. Eighteen full-term
healthy neonates were enrolled in this study. In the cord and d-5
blood samples, the OC levels were determined by three different
methods to examine the intact OC by immunoradiometric assay
(IRMA), Gla-OC, and Glu-OC. Serum vitamin K fractions,
hepaplastin test, and type 1 procollagen carboxyl extension
peptide were also determined. Urine samples were also collected
from the first voiding and on d 5 to determine urinary pyridino-
line, deoxypyridinoline, and $\gamma$-carboxylated glutamic acid. Se-
rum levels of phylloquinone (PK) and menaquinone (MK)-4
increased on d 5 following vitamin K administration and in-
creased intake in breast milk and/or formula. The OC levels
determined by IRMA did not change between cord and d-5 blood
\end{abstract}
Natural vitamin $\mathrm{K}$ is composed of $\mathrm{PK}$ and $\mathrm{MK}$. MK is further divided according to the length of its side chain. The main circulating vitamin $\mathrm{K}$ in human serum is $\mathrm{PK}$ and $\mathrm{MK}-7$ (1). Vitamin $\mathrm{K}$ acts as a co-factor for $\gamma$-carboxylase, known as a key enzyme for producing competent coagulation factors in the liver. Its deficiency is a relatively common condition in neonates and has long been a major cause of serious bleeding diseases in newborn babies. Neonatal vitamin K deficiency may be attributed to the following causes: the human placenta

Received February 2, 2001; accepted November 27, 2001.

$\dagger$ Deceased.

Correspondence: Masaaki Shima, M.D., Department of Developmental Medicine (Pediatrics), D-5, Osaka University Graduate School of Medicine, Osaka 565-0871, Japan; e-mail: masa@ped.med.osaka-u.ac.jp

Supported in part by a Grant-in Aid from the Ministry of Education, Science, Sports and Culture, and a Grant-in Aid from the Research Society for Metabolic Bone Diseases.

Kanji Yamaoka is deceased.

DOI: 10.1203/01.PDR.0000032073.63946.88 samples, but the Gla-OC level increased remarkably and Glu-OC reduced to a negligible level. OC in cord blood is mainly Glu-OC, and Glu-OC is replaced with Gla-OC within $5 \mathrm{~d}$ of life after vitamin $\mathrm{K}$ supplement. The IRMA assay fails to distinguish Gla-OC from Glu-OC and caution is needed to estimate bone turnover with this method in the perinatal period. (Pediatr Res 52: 656-659, 2002)

OC, osteocalcin

\section{Abbreviations}

Gla-OC, $\gamma$-carboxylated osteocalcin

Glu-OC, non- or undercarboxylated osteocalcin

IRMA, immunoradiometric assay

PK, phylloquinone

MK, menaquinone

PICP, type 1 procollagen carboxyl extension peptide

$\boldsymbol{\gamma}$-Gla, $\gamma$-carboxylated glutamic acid

Pyr, pyridinoline

D-Pyr, deoxypyridinoline has a limited capacity to transfer vitamin $\mathrm{K}(2)$; and maternal breast milk contains a low level of vitamin $\mathrm{K}$, especially in the early phase of lactation (3). Based on these facts, prophylactic administration of vitamin $\mathrm{K}$ to newborns has been recommended in many countries, though dosages and schedules of supplement differ among those countries. A number of studies have reported that vitamin $\mathrm{K}$ supplementation successfully decreased the incidence of neonatal intracranial hemorrhage and melena (4-6).

Another important substrate of $\gamma$-carboxylase is $\mathrm{OC}$, produced in osteoblasts. OC is the most abundant noncollagenous protein in bone, containing 49 amino acid residues. It is often used as a marker of osteoblastic activity and bone formation (7). OC has an affinity with calcium hydroxyapatite but does not bind to it until the OC becomes $\gamma$-carboxylated in the osteoblasts (8). Vitamin $\mathrm{K}$ is essential for the $\gamma$-carboxylation in three glutamate residues of the OC peptide (positions of amino acids 17, 21, and 24) (7). Thus, insufficiency of vitamin 
$\mathrm{K}$ results in the secretion of Glu-OC in osteoblasts. Consequently, the bone tissue may become frail. In adults, an increase in serum Glu-OC was demonstrated to increase the risk of bone fracture $(9,10)$. Some investigators have reported that adult patients with hip fractures or spinal crush fractures had very low concentrations of circulating PK and MK $(11,12)$.

Bone turnover in neonates is much higher than in adults with increased OC and type 1 procollagen carboxyl extension peptide (PICP) levels (13). With regard to OC, $>90 \%$ of newly synthesized OC is deposited to bone in vitamin K-supplemented young animals (7). However, the effects of vitamin K on OC metabolism in newborn infants remain to be determined. We have previously reported that the OC concentration in cord blood serum was high (14). However, simultaneous measurement of urinary $\gamma$-Gla indicated that the products of $\gamma$-carboxylase were too low to presume that such a high concentration of serum OC was fully $\gamma$-carboxylated antenatally. Thus, we hypothesized the presence of Glu-OC in the cord blood to explain the discrepancy of the high OC level with relatively low urinary $\gamma$-Gla, because the conventional assay was unable to distinguish Gla-OC from Glu-OC. In this study, we measured Gla-OC and Glu-OC separately, and examined the effects of vitamin $\mathrm{K}$ on bone and $\mathrm{OC}$ metabolism.

\section{MATERIALS AND METHODS}

This prospective study was approved by the Review Board at Osaka University and conducted in 18 neonates born at Osaka University Hospital with informed consent having been obtained from their parents. Mature and healthy neonates were selected randomly. The durations of pregnancy were 38-41 wk (mean 39 wk $5 \mathrm{~d} \pm 6$ d). Each newborn baby weighed between 2900 and $3300 \mathrm{~g}$ (mean $3158 \pm 358 \mathrm{~g}$ ) and Apgar scores were over 9 at $5 \mathrm{~min}$ after birth. Most of the babies were given formula for about $2 \mathrm{~d}$ until lactation of their mothers was established. Vitamin $\mathrm{K}$ was administered to all neonates twice within the first $5 \mathrm{~d}$. The first administration was within $24 \mathrm{~h}$ after birth, and the second just before discharge on $\mathrm{d} 5$. On each occasion, 2 mg of MK syrup (MK-4; vitamin K2 syrup, Eisai Co., Tokyo, Japan), diluted to $10 \mathrm{~mL}$ by $10 \%$ glucose solution, was given orally. Umbilical cord blood samples were collected from the umbilical vein immediately after cord clamping. On d 5 , blood was obtained by venipuncture early in the morning before the second administration of vitamin $\mathrm{K}$. A portion of each blood sample was obtained as sodium citrate-added plasma, and the rest was obtained as serum. The samples were separated immediately after collection. A part of each plasma sample was then taken to measure the hepaplastin time, and the remainder was stored at $-80^{\circ} \mathrm{C}$ until the measurements of $\mathrm{OC}$, vitamin $\mathrm{K}$ fractions, and other biochemical markers. Urine samples were collected by applying plastic bags soon after birth and on $\mathrm{d} 5$. The samples were stored at $-80^{\circ} \mathrm{C}$ for determinations of urinary $\gamma$-Gla, Pyr, and D-Pyr. Serum intact OC levels were measured by IRMA (Mitsubishi Kagaku BioClinical Lab, Tokyo, Japan). The reference value in normal healthy adults is $2.3-9.9 \mathrm{ng} / \mathrm{mL}$. The lowest detection limit is $1.0 \mathrm{ng} / \mathrm{mL}$. Gla-OC and Glu-OC were measured by RIA (Takara Shuzo Co., Ohtsu, Japan). The antibody for determi- nation of Gla-OC recognizes the position of the 17th Gla residue, whereas the antibody for Glu-OC measurement recognizes the positions of 21 and 24 Glu residues. The lowest detection limits were $1.0 \mathrm{ng} / \mathrm{mL}$ and $0.5 \mathrm{ng} / \mathrm{mL}$, respectively. Serum vitamin K (PK, MK-4, and MK-7) levels were assayed by HPLC/ECD-FL (Mitsubishi Kagaku Bio-Clinical Lab). The lowest detection limits were $0.10 \mathrm{ng} / \mathrm{mL}, 0.10 \mathrm{ng} / \mathrm{mL}$, and 0.40 $\mathrm{ng} / \mathrm{mL}$, respectively. Urinary $\gamma$-Gla was determined as reported previously (14). Total activity of vitamin K-dependent coagulation factors II, VII, X was examined by the hepaplastin test (15). We used a commercially available kit (Eisai Co.), and the normal values in adults are $100 \pm 30 \%$. PICP was determined by RIA, Pyr by HPLC, and D-Pyr by EIA (Mitsubishi Kagaku Bio-Clinical Lab). Data are presented as mean \pm SD. All statistical analyses were performed with the paired $t$ test using StatView 4.02J (SAS Institute, Cary, NC, U.S.A.) on an Apple Macintosh computer.

\section{RESULTS}

Blood levels of vitamin $K$ components. The vitamin $\mathrm{K}$ components of PK, MK-4, and MK-7 in the cord blood are shown in Figure 1, and the values were comparable to the previous report (16). After vitamin $\mathrm{K}$ administration and increased intake in breast milk and/or formula, the PK and MK-4 levels increased, although the values varied widely among individuals. PK is likely to be provided via either formula or breast milk $(3,17)$. In contrast, MK-7 in all the samples remained below detection limits and showed no distinct change. The results of hepaplastin testing are shown in Figure 2. The mean value of hepaplastin test increased from $46.6 \%$ to $71.8 \%(p<0.01)$. Similarly, urinary excretion of $\gamma$-Gla significantly increased from $94.3 \mathrm{nmol} / \mathrm{mg}$ creatinine $(\mathrm{mgCr})$ to $146.3 \mathrm{nmol} / \mathrm{mgCr}$ after vitamin $\mathrm{K}$ administration $(p<0.001)$.

Comparison of three assays of osteocalcin. The OC levels in cord blood and blood samples obtained $5 \mathrm{~d}$ after delivery were examined by three different methods (Fig. 3). The mean OC concentration determined by IRMA in $\mathrm{d}-5$ blood was similar to the value in cord blood (cord OC, $23.9 \mathrm{ng} / \mathrm{mL} ; \mathrm{d} 5$,
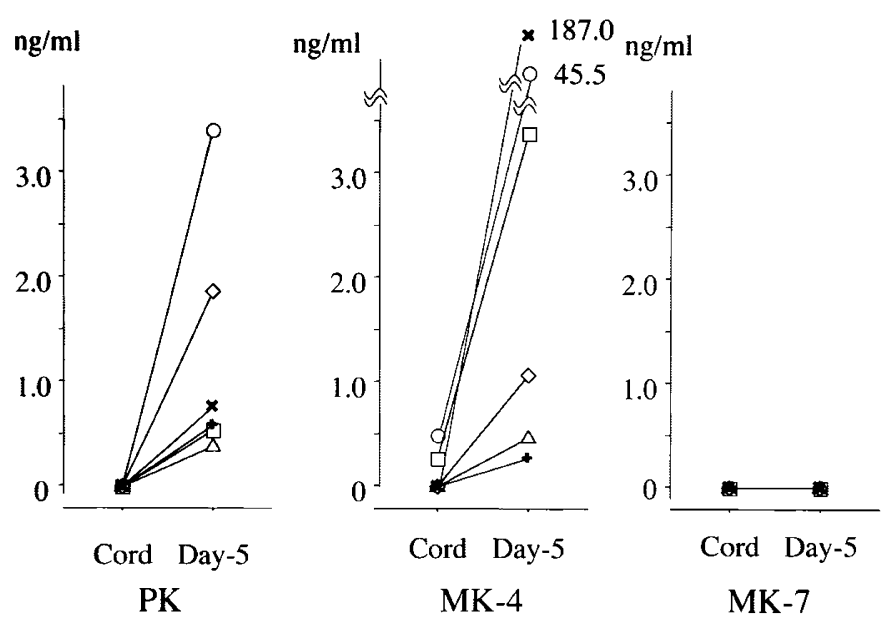

Figure 1. Serum levels of vitamin $\mathrm{K}$ fractions in cord blood and in d-5 blood samples. $P K$, phylloquinone; $M K$, menaquinone. In MK, MK-4 and MK-7 were separately examined as described in "Materials and Methods." 
A.

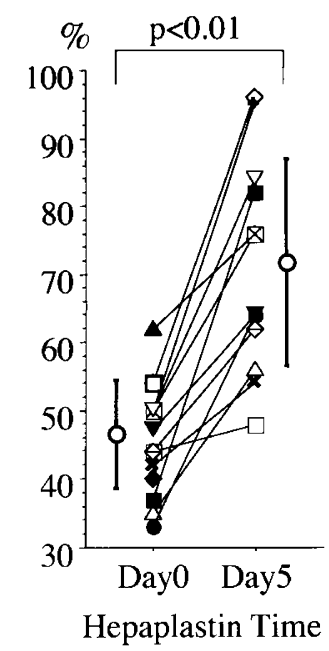

B.

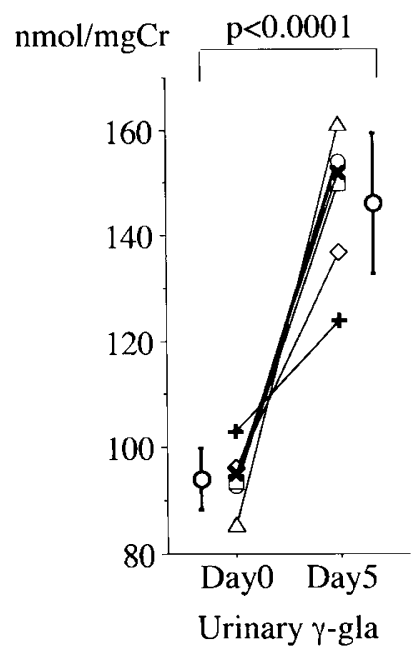

Figure 2. (A) Comparison of hepaplastin time between cord blood and d-5 blood. Data from the same neonates are bound with lines. Mean and SD are also shown. $(B)$ Urinary $\gamma$-Gla excretion was compared between the first voided urine samples and those obtained on $\mathrm{d} 5$.



Intact $\mathrm{OC}$

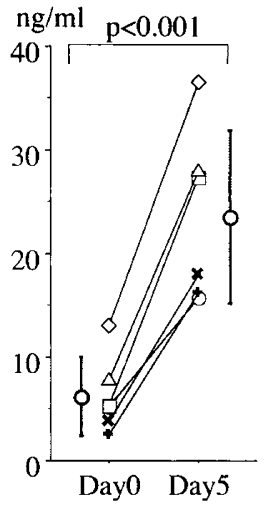

Gla-OC

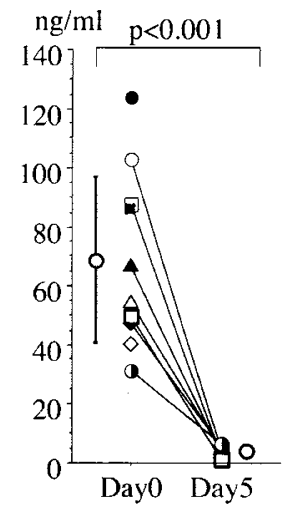

Glu-OC

Figure 3. The measurements of $\mathrm{OC}$ in three methods. Intact $\mathrm{OC}$ was determined by IRMA. Data of cord blood (day 0 ) and d-5 blood (day 5) from the same neonates are bound with lines. Mean and SD are also shown.

$21.1 \mathrm{ng} / \mathrm{mL}$ ). These results were much higher than those of healthy adults. Gla-OC increased from very low values to levels higher than those of normal adults at d 5. As for Glu-OC, all cases showed an extremely high level in cord blood, compared with the level in healthy adults, which is just between 2 and $3 \mathrm{ng} / \mathrm{mL}$. After vitamin $\mathrm{K}$ administration, blood Glu-OC levels at $\mathrm{d} 5$ decreased to the normal range of healthy adults.

Bone metabolism turnover is high in neonates. Bone metabolism markers other than OC were also determined (Fig. 4). PICP, a bone formation marker, proved to be high in cord blood, and became even higher at d $5(p<0.01)$. Two bone resorption markers, Pyr and D-Pyr, were increased compared with the adult standard. Both Pyr and D-Pyr tended to increase on $\mathrm{d} 5$, but only the latter was statistically significant. All three markers showed high levels, similar to previous reports (18, 19), suggesting a high turnover of bone in the perinatal period.

A.

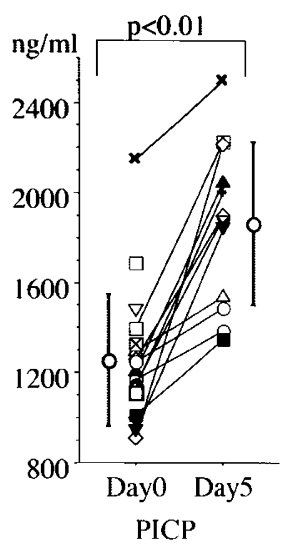

B.

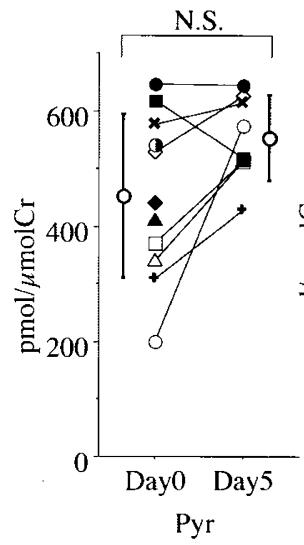

C.

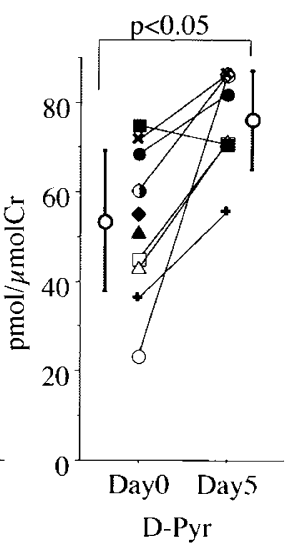

Figure 4. (A) Comparison of bone formation marker of PICP between cord and d-5 blood. Mean and SD are also shown. Data from the same neonates are bound with lines. Levels of $\operatorname{Pyr}(B)$ and D-Pyr $(C)$ in the first voided urine samples and those obtained on $\mathrm{d} 5$.

\section{DISCUSSION}

In this study, we clearly showed that the most of the $\mathrm{OC}$ in cord blood serum was Glu-OC, as was speculated previously (14). A high turnover of bone in the perinatal period may result in the overproduction of $\mathrm{OC}$, independent of the capacity for $\gamma$-carboxylation. Thus, under the condition of vitamin $\mathrm{K}$ deficiency, a large amount of Glu-OC is produced but fails to deposit in the bone tissue. Glu-OC then enters the circulation and becomes remarkably high compared with normal adults. When vitamin $\mathrm{K}$ was administered, $\gamma$-carboxylation was enhanced not only in the liver but also in osteoblasts, leading to increases in the measurement of hepaplastin test and Gla-OC. Although there was no difference in $\mathrm{OC}$ level determined by IRMA between the cord and d-5 serum, the main fraction in the cord blood was Glu-OC whereas that at $\mathrm{d} 5$ was Gla-OC. Due to the short half-life of OC (7), Gla-OC was considered to be synthesized de novo in osteoblasts with $\gamma$-carboxylation by $\mathrm{d} 5$.

The drastic changes in Gla-OC and hepaplastin time may reflect a deficiency of vitamin $\mathrm{K}$ in utero. Levels of vitamin $\mathrm{K}$ fractions were undetectable or close to the detection limits in this assay, as was reported previously $(2,16)$. Although serum MK-4 levels were increased after oral administration, there was a great difference in the values, reflecting a difference in resorption capacity in each neonate. The result was compatible with the previous report that oral administration of vitamin $\mathrm{K}$ was less effective than intramuscular administration for the prevention of vitamin $\mathrm{K}$ deficient bleeding (20).

Bone turnover is enhanced in neonates, and the PICP level on $\mathrm{d} 5$ was significantly increased compared with that in cord blood. However, the OC level examined by IRMA showed no difference. These results may be explained by the fact that OC, produced in $\gamma$-carboxylated form after vitamin $\mathrm{K}$ administration, has the capacity to bind to the hydroxyapatite in bone. Thus, osseous clearance of $\mathrm{OC}$ was increased, preventing the increase of OC in d-5 blood.

The mechanism for a relatively low Gla-OC level at d 5 compared with Glu-OC at d 0 remains unknown. One of the possible explanations is the presence of partially $\gamma$-carboxy- 
lated $\mathrm{OC}$ at the 21 or 24 position of glutamic acid in $\mathrm{d}-5$ serum, which the assay for Gla-OC fails to detect.

In summary, most of the OC in cord serum was Glu-OC, and was replaced by Gla-OC by d 5 due to vitamin $\mathrm{K}$ administration and increased intake in breast milk and formula. Measurement of OC may be useful to evaluate neonatal bone metabolism, but for interpretation of the measurement, we must be careful to examine bone turnover with the IRMA method.

\section{REFERENCES}

1. Shino M 1988 Determination of endogenous vitamin K (phylloquinone and menaquinone-n) in plasma by high-performance liquid chromatography using platinum oxide catalyst reduction and fluorescence detection. Analyst 113:393-397

2. Shearer MJ 1995 Vitamin K. Lancet 345:229-234

3. Greer F, Marshall S, Cherry J, Suttie J 1991 Vitamin K status of lactating mothers, human milk, and breast-feeding infants. Pediatrics 88:751-756

4. Vitamin K Ad Hoc Task Force 1993 Controversies concerning vitamin K and the newborn. Pediatrics 91:1001-1003

5. Cornelissen M, von Kries R, Loughnan P, Schubiger G 1997 Prevention of vitamin $\mathrm{K}$ deficiency bleeding: efficacy of different multiple oral dose schedules of vitamin $\mathrm{K}$. Eur J Pediatr 156:126-130

6. Hanawa Y, Maki M, Matsuyama E, Tada H, Urayama T, Yamada K, Mori H, Nagao T, Terao T, Mikami S, et al 1990 The third nationwide survey in Japan of vitamin K deficiency in infancy. Acta Paediatr Jpn 32:51-59

7. Hauschka P, Lian J, Cole D, Gundberg C 1989 Osteocalcin and matrix Gla protein: vitamin K-dependent proteins in bone. Physiol Rev 69:990-1047

8. Koshihara Y, Hoshi K 1997 Vitamin K2 enhances osteocalcin accumulation in the extracellular matrix of human osteoblasts in vitro. J Bone Miner Res 12:431-438
9. Szulc P, Chapuy M, Meunier P, Delmas P 1996 Serum undercarboxylated osteocalcin is a marker of the risk of hip fracture: a three year follow-up study. Bone 18:487-488

10. Vergnaud P, Garnero P, Meunier P, Breart G, Kamihagi K, Delmas P 1997 Undercarboxylated osteocalcin measured with a specific immunoassay predicts hip fracture in elderly women: the EPIDOS Study. J Clin Endocrinol Metab 82:719-724

11. Vermeer C, Gijsbers B, Craciun A, 191S Groenen-van Dooren M, Knapen M 1996 Effects of Vitamin K on bone mass and bone metabolism. J Nutr 126:1187S-1191S

12. Shiraki M, Shiraki Y, Aoki C, Miura M 2000 Vitamin K2 (menatetrenone) effectively prevents fractures and sustains lumbar bone mineral density in osteoporosis. J Bone Miner Res 15:515-521

13. Tsukahara H, Watanabe Y, Hirano S, Tsubokura H, Kimura K, Mayumi M 1999 Assessment of bone turnover in term and preterm newborns at birth: measurement of urinary collagen crosslink excretion. Early Hum Dev 53:185-191

14. Shima M, Seino Y, Tanaka Y, Yabuuchi H, Tsutsumi C, Moriuchi S 1985 Bone $\gamma$-carboxyglutamic acid containing protein in the perinatal period. Acta Paediatr Scand 74:674-677

15. Owren PA, Strande OK 1969 Normotest. Farmakoterapi 25:14-26

16. Hiraike H, Kimura M, Itokawa Y 1988 Distribution of K vitamins (phylloquinone and menaquinones) in human placenta and maternal and umbilical cord plasma. Am J Obstet Gynecol 158:564-569

17. Shirahata A, Nakamura T, Ariyoshi N 1991 Vitamin K 1 and K2 contents in blood, stool, and liver tissues of neonates and young infants. In: Suzuki S, Hathaway W, Bonnar J, Sutor A (eds) Perinatal Thrombosis and Hemostasis. Springer-Verlag, New York, pp 213-223

18. Lieuw AFM, Sierra RI, Specker BL 1995 Carboxy-terminal propeptide of human type I collagen and pyridinium cross-links as markers of bone growth in infants 1 to 18 months of age. J Bone Miner Res 10:849-853

19. Crofton PM, Shrivastava A, Wade JC, Stephen R, Kelnar CJ, Lyon AJ, McIntosh N 1999 Bone and collagen markers in preterm infants: relationship with growth and bone mineral content over the first 10 weeks of life. Pediatr Res 46:581-587

20. Autret-Leca E, Jonville-Bera AP 2001 Vitamin K in neonates: how to administer, when and to whom. Paediatr Drugs 3:1-8 